\title{
Dietary Inflammatory Index Score and Its Association with Body Weight, Blood Pressure, Lipid Profile, and Leptin in Indonesian Adults
}

\author{
Harry Freitag Luglio Muhammad 1,2,*, Marleen A. van Baak ${ }^{2}$, Edwin C. Mariman ${ }^{2}$, \\ Dian Caturini Sulistyoningrum ${ }^{1}$, Emy Huriyati ${ }^{1}$, Yi Yi Lee ${ }^{3}{ }^{3}$ and \\ Wan Abdul Manan Wan Muda ${ }^{4}$ \\ 1 Department of Nutrition and Health, Universitas Gadjah Mada, Yogyakarta 55281, Indonesia; \\ dian.csulis@gmail.com (D.C.S.); emy_huriyati@yahoo.com (E.H.) \\ 2 NUTRIM School of Translational Nutrition and Metabolism, Department of Human Biology, \\ Maastricht University, 6200 MD Maastricht, The Netherlands; \\ m.vanbaak@maastrichtuniversity.nl (M.A.v.B.); e.mariman@maastrichtuniversity.nl (E.C.M.) \\ 3 International Institute for Global Health, United Nations University, Kuala Lumpur 16150, Malaysia; \\ leeyy.yiyi@gmail.com \\ 4 Center for Southeast Asian Studies, Kyoto University, Kyoto 606-8501, Japan; wanmanan@gmail.com \\ * Correspondence: harryfreitag@ugm.ac.id; Tel.: +62-274-547-775
}

Received: 23 November 2018; Accepted: 25 December 2018; Published: 11 January 2019

\begin{abstract}
It was previously reported that dietary intake is an important trigger for systemic inflammation and one of the lifestyle factors for the development of cardiovascular diseases. The aim of this study was to evaluate the association between Dietary Inflammatory Index (DII) score and body weight, blood pressure, lipid profile and leptin in an Indonesian population. This was a cross-sectional study conducted in 503 Indonesian adults. The DII score was calculated based on data of 30 nutrients and food components. Anthropometric profile, blood pressure, lipid profile, and leptin were measured. The association of these variables with the DII score was analyzed. The DII score was not associated with body weight, body mass index (BMI), body fat, waist circumference, hip circumference, systolic and diastolic blood pressure, triglycerides, and high-density lipoprotein (HDL) (both unadjusted and after adjustment for covariates). However, plasma leptin concentration was significantly associated with the DII score $(\mathrm{B}=0.096, p=0.020)$. Plasma leptin also increased significantly across tertiles of the DII score (ANCOVA, $p=0.031$ ). This positive association between the DII score and plasma leptin concentration suggests a role for the inflammatory properties of the diet in regulating adipose tissue inflammation.
\end{abstract}

Keywords: dietary inflammatory index; obesity; triglyceride; HDL; leptin

\section{Introduction}

Obesity affects millions of adults and children and this state of over-nutrition is responsible for an increasing economic and health burden worldwide [1,2]. Adiposity is associated with increased risk for non-communicable diseases (NCDs) such as type 2 diabetes mellitus, dyslipidemia, heart disease, and hypertension [1]. One of the mechanisms which may explain the interaction between obesity and the development of NCDs is systemic and adipose tissue inflammation [3,4]. The excess of adipose tissue induces increments in the production of leptin and pro-inflammatory cytokines as well as immune cell infiltration [4]. In addition, a reduction in anti-inflammatory immune cells in adipose tissue of individuals with obesity has been reported $[5,6]$. This combination leads to an inflammatory state in adipose tissue as well as the circulation of individuals with obesity [4]. 
Inflammation is also influenced by environmental factors (e.g., lifestyle, diet, physical activity) and genetic background [7]. It has been reported previously that the dietary pattern has an important role in affecting circulating inflammatory markers in adults [8]. Recently, a new tool has been developed to assess the inflammatory properties of the diet: the Dietary Inflammatory Index (DII) [9]. In this index, intake of nutrient and non-nutrient components of the diet are calculated and compiled into an index. The score on this index has been shown to be associated with systemic inflammation [10-12]. In the cross-sectional Spanish PREDIMED (Prevención con Dieta Mediterránea) study the DII score was associated with body weight and other anthropometric measures [13]. In the Spanish SUN (Seguimiento Universidad de Navarra) cohort, the DII score was associated with annual weight gain [14]. We have shown that the DII score was associated with weight regain following a weight loss program in Dutch overweight and obese individuals [15].

Inflammation is associated with the development of chronic diseases and is an important link between obesity and cardiovascular diseases $[3,16]$. It was previously suggested that inflammation plays an important role in the disturbance of blood pressure and lipid profile $[3,16,17]$. This notion is supported by several studies in western societies which showed that the inflammatory properties of the diet were associated with early predictors of cardiovascular diseases such as hypertension, and higher plasma triglyceride and lower high-density lipoprotein (HDL) cholesterol concentrations [18-20].

Currently, there is limited evidence on the application of the DII in Asian countries. To our knowledge, there is only one report from a small cross-sectional study conducted in female school teachers in Myanmar, which found no association between the DII score and overweight [21]. Evaluation of the DII in different population settings is important because dietary practices vary amongst cultures and might have an impact on the DII value. Additionally, because other factors such as environments, lifestyle, and genetic background are also different among population settings, this might influence the relationship between the DII score and metabolic health. Therefore, the aim of this study was to evaluate the associations between the DII score and body weight, blood pressure, lipid profile, and leptin in an Indonesian population.

\section{Materials and Methods}

These analyses are part of an Indonesian cohort study that investigates the effect of lifestyle and genetic variation on metabolic syndrome in adults. It is a secondary cross-sectional analysis of baseline data of this study that was carried out among adult men and women between 19 and 56 years of age, living in the urban area of Yogyakarta, Indonesia. A total of 503 individuals, stratified for sex, were recruited from randomly selected neighborhoods from five sub-districts which were selected.

The inclusion criteria were: permanent residence (at least 2 years) in the area and agreement to become subject of this study by signing the informed consent. The exclusion criteria were: diagnosis of chronic diseases such as diabetes, cardiovascular disease, or cancer, pregnancy at the time the study was conducted, current or prior cigarette smoker status, strict diet, and problems with walking or conducting physical activity in the prior 6 months. Subjects who consumed drugs to treat the clinical features of cardiovascular diseases (such as blood pressure-, lipid-, and/or glucose-lowering drugs) were also excluded from this study. Ethical clearance was obtained from the Medical and Health Research Ethics Committee (MHREC) Faculty of Medicine, Universitas Gadjah Mada, Indonesia (KE/FK/791/EC/2015). This study followed the ethical guidelines of the 1975 Declaration of Helsinki.

Obesity status was defined by body mass index (BMI) and calculated by dividing body weight with the square of height. Body composition was defined by percent body fat. Body weight and body fat were measured using a digital body mass scale and bioelectrical impedance $(0.01 \mathrm{~kg}$ precision, Omron Karada Scan HBF-375, Osaka, Japan). Height was measured using a wall-mounted tape measure $(0.1 \mathrm{~cm}$ precision, GEA medical, Jakarta, Indonesia). Waist and hip circumference were measured using a non-elastic tape $(0.1 \mathrm{~cm}$ precision). All anthropometric measurements were done by trained personnel using calibrated instruments. 
Blood pressure was measured using Omron HEM 7120 Automatic Blood Pressure (Omron, Japan). This measurement was done after at least 10 minutes rest from recent activity and the participants were asked to sit in a comfortable sitting position with their left arm fully exposed and resting on a supportive surface at the heart level. Blood pressures were measured on the left arm using appropriate cuff size.

Data on dietary intake were collected using a validated Semi-Quantitative Food Frequency Questionnaire (SQ-FFQ) and the analysis was based on Indonesian food database and United States Department of Agriculture [22]. Data of habitual consumption of food items that were collected using the SQ-FFQ were translated into daily intake [23]. Data collection for dietary intake was done by a face-to-face interview between trained nutritionists and subjects.

The Dietary inflammatory Index $\left(\mathrm{DII}^{\circledR}\right)$ score is a calculated parameter that gives an overall picture of the inflammatory properties of the diet. An individual's diet is considered more pro-inflammatory when the DII score is more positive, while the diet is considered more anti-inflammatory when the DII score is more negative. The DII score was calculated according to Shivappa et al. [9]. The calculation of the dietary inflammatory index score was based on 30 nutrients and food components including total energy, protein, carbohydrate, total fat, saturated fat, trans fat, mono-unsaturated fatty acid (MUFA), poly-unsaturated fatty acid (PUFA), omega-3 fatty acid, omega-6 fatty acid, cholesterol, fibre, magnesium, iron, selenium, zinc, vitamin $\mathrm{A}$, vitamin $\mathrm{C}$, vitamin $\mathrm{D}$, vitamin $\mathrm{E}$, thiamin, riboflavin, vitamin B6, vitamin B12, folate, niacin, beta-carotene, alcohol, caffeine, and tea. No data were available for the other dietary factors included by Shivappa et al. [9] in their dietary inflammation index such as rosemary, oregano, pepper, turmeric, saffron, onion, ginger, garlic, and polyphenols (i.e., isoflavones and anthocyanidins). To derive the individual DII scores, the global average intake (taken from Shivappa et al. [9]) was subtracted from the reported daily intake of each nutrient in the FFQ and divided by the standard deviation of the global daily intake, rendering a z-score which was converted into a centered percentile score. This score was then multiplied with an overall inflammatory effect score. All 30 (out of 48) included individually calculated nutrient-specific effect scores were then summed to obtain the DII score.

Data on physical activity was collected using the International Physical Activity Questionnaire (IPAQ) [24]. This questionnaire contains information on the intensity and duration of several activities including work/job, transportation, house-related work and maintenance, recreation, exercise and leisure-time physical activity. Each activity has a unique metabolic equivalent of task (MET) score, which represents the amount of energy used for a certain type of activity. In order to obtain an overall picture of the individual's physical activity, all the activities that have been reported in IPAQ are transformed into MET-minutes/week. The SQ-FFQ and IPAQ were developed, validated and used before [23-25].

From each participant a $10-\mathrm{mL}$ blood sample was collected in ethylenediaminetetraacetic acid (EDTA)-containing tubes. After collection, blood plasma and buffy coat were separated by centrifugation. Plasma HDL cholesterol and triglyceride concentration were measured using the cholesterol oxidase phenol 4-aminoantipyrine peroxidase (CHOD-PAP) and glycerol phosphate oxidase (GPO) methods, respectively (Diasys, Holzheim, Germany). Plasma leptin concentration was measured using an enzyme-linked immunosorbent assay (DRG, Springfield Township, NJ, USA).

Statistical analyses were conducted using JASP (University of Amsterdam, the Netherlands) [26]. The relationships between the DII score as independent variable and body weight, blood pressure, lipid profile and leptin concentration as dependent variables were analyzed by linear regression analysis (Model 0, unadjusted). Adjustments for age, sex, physical activity and energy intake, and BMI where relevant, were done. Model I represents a regression analysis with adjustment for age, sex, and BMI (for blood pressure, triglycerides, HDL and leptin). Model II represents a regression analysis with adjustment for age, sex, energy intake, physical activity and BMI (for blood pressure, triglycerides, HDL and leptin). In addition, we made groups based on tertiles of the DII score and compared the variables by ANOVA (analysis of variance) or ANCOVA (Analysis of covariance). 
The ANCOVA analysis adjusted for age, sex, energy intake, and physical activity when analyzing differences in anthropometric measures among DII score tertiles. For analysis of blood pressure, lipid profile, and leptin differences between DII score tertiles, ANCOVA adjusting for age, sex, body mass index, energy intake, and physical activity was used.

\section{Results}

Characteristics of study participants are shown in Table 1. In this study, 503 adults (men 50.1\% and women $49.9 \%$ ) living in Yogyakarta were investigated. Data on the characteristics of men and women separately can be found in Supplementary Table S1.

Table 1. Characteristics of study participants.

\begin{tabular}{|c|c|}
\hline Characteristics & All $(n=503)$ \\
\hline Age (years) & $41.6 \pm 10.2$ \\
\hline \multicolumn{2}{|l|}{ Anthropometric measures } \\
\hline Body weight (kg) & $62.6 \pm 13.1$ \\
\hline Height (cm) & $158.5 \pm 9.0$ \\
\hline Body mass index $\left(\mathrm{kg} / \mathrm{m}^{2}\right)$ & $24.9 \pm 5.0$ \\
\hline Body fat $(\%)$ & $27.5 \pm 8.7$ \\
\hline Waist circumference $(\mathrm{cm})$ & $86.2 \pm 12.7$ \\
\hline Hip circumference (cm) & $93.9 \pm 11.2$ \\
\hline Waist-to-hip ratio & $0.92 \pm 0.07$ \\
\hline \multicolumn{2}{|l|}{ Blood pressure } \\
\hline Systolic (mmHg) & $128.6 \pm 25.2$ \\
\hline Diastolic (mmHg) & $79.7 \pm 14.8$ \\
\hline \multicolumn{2}{|l|}{ Metabolic profile } \\
\hline Triglycerides (mmol/L) & $1.57 \pm 0.82$ \\
\hline HDL cholesterol (mmol/L) & $1.18 \pm 0.47$ \\
\hline Leptin $(\mathrm{ng} / \mathrm{mL})$ & $7.3 \pm 8.8$ \\
\hline Physical activity (METs-min/week) & $5781 \pm 5932$ \\
\hline \multicolumn{2}{|l|}{ Dietary intake } \\
\hline Energy (kJ/day) & $10838 \pm 4789$ \\
\hline Protein (energy \%) & $12.5 \pm 3.4$ \\
\hline Fat (energy \%) & $23.1 \pm 10.6$ \\
\hline Carbohydrate (energy \%) & $64.3 \pm 10.8$ \\
\hline Dietary inflammatory index score & $1.01 \pm 7.29$ \\
\hline$\%$ overweight ${ }^{a}$ & 45.9 \\
\hline$\%$ obese $^{b}$ & 14.9 \\
\hline
\end{tabular}

Values are presented as mean \pm standard deviation. ${ }^{a}$ body mass index $\geq 25 \mathrm{~kg} / \mathrm{m}^{2}$ or higher, ${ }^{b}$ body mass index $\geq 30 \mathrm{~kg} / \mathrm{m}^{2}$ or higher, ${ }^{\mathrm{a}, \mathrm{b}}$ percent of total number of study participants. HDL = high-density lipoprotein; MET = metabolic equivalent of task.

Data of dietary intake of study participants are shown and compared with global data of dietary intake based on Shivappa et al. [9] (Table 2). Compared to global averages, participants in this study had a relatively high intake of pro-inflammatory components such as total energy, carbohydrate, iron, and vitamin B12. They had a relatively low intake of anti-inflammatory components such as omega 3 fatty acid, omega 6 fatty acid, niacin, vitamin A, vitamin D, vitamin E, alcohol, and caffeine, but a relatively high intake of other anti-inflammatory components such as fiber, magnesium, selenium, vitamin $C$, folic acid, and tea. 
Table 2. Comparison of global dietary intake and dietary intake of Indonesian adults.

\begin{tabular}{|c|c|c|}
\hline Intake & Global Dietary Intake & Dietary Intake of Study Participants \\
\hline \multicolumn{3}{|c|}{ Pro-inflammatory components } \\
\hline Carbohydrate $(\mathrm{g})$ & $272.2 \pm 40.0$ & $416.9 \pm 202.8$ \\
\hline Cholesterol (mg) & $279.4 \pm 51.2$ & $177.8 \pm 161.8$ \\
\hline Energy (kj) & $8606 \pm 1414$ & $10838 \pm 4789$ \\
\hline Iron (mg) & $13.35 \pm 3.71$ & $18.1 \pm 9.8$ \\
\hline Protein (g) & $79.4 \pm 13.9$ & $80.8 \pm 41.9$ \\
\hline Saturated fat (g) & $28.6 \pm 8.0$ & $25.7 \pm 19.6$ \\
\hline Total fat $(\mathrm{g})$ & $71.4 \pm 19.4$ & $66.6 \pm 45.9$ \\
\hline Trans fatty acid (g) & $3.15 \pm 3.75$ & $2.82 \pm 4.72$ \\
\hline Vitamin $B_{12}(\mu \mathrm{g})$ & $5.15 \pm 2.70$ & $7.38 \pm 9.54$ \\
\hline \multicolumn{3}{|c|}{ Anti-inflammatory components } \\
\hline Alcohol $(\mathrm{g})$ & $19.98 \pm 3.72$ & $0.03 \pm 0.07$ \\
\hline Beta-carotene $(\mu \mathrm{g})$ & $3718 \pm 1720$ & $3696 \pm 3721$ \\
\hline Caffeine $(\mathrm{g})$ & $8.05 \pm 6.67$ & $0.09 \pm 0.10$ \\
\hline Fiber $(\mathrm{g})$ & $18.8 \pm 4.0$ & $24.3 \pm 13.5$ \\
\hline Folic acid $(\mu \mathrm{g})$ & $273.0 \pm 70.7$ & $403.0 \pm 339.4$ \\
\hline Magnesium (mg) & $310.1 \pm 139.4$ & $392.1 \pm 278.2$ \\
\hline MUFA (g) & $27.0 \pm 6.1$ & $29.5 \pm 23.1$ \\
\hline Niacin (mg) & $25.9 \pm 11.8$ & $19.57 \pm 9.14$ \\
\hline Omega 3 fatty acids (g) & $1.06 \pm 1.06$ & $0.46 \pm 0.47$ \\
\hline Omega 6 fatty acids (g) & $10.80 \pm 7.50$ & $0.86 \pm 0.80$ \\
\hline PUFA (g) & $13.88 \pm 3.76$ & $13.40 \pm 9.64$ \\
\hline Riboflavin (mg) & $1.70 \pm 0.79$ & $1.97 \pm 1.72$ \\
\hline Selenium $(\mu \mathrm{g})$ & $67.0 \pm 25.1$ & $103.0 \pm 49.6$ \\
\hline Black/green tea (g) & $1.69 \pm 1.53$ & $2.36 \pm 2.60$ \\
\hline Thiamin (mg) & $1.70 \pm 0.66$ & $1.39 \pm 0.71$ \\
\hline Vitamin A (RE) & $983.9 \pm 518.6$ & $574.3 \pm 508.0$ \\
\hline Vitamin $\mathrm{B}_{6}(\mathrm{mg})$ & $1.47 \pm 0.74$ & $4.59 \pm 3.71$ \\
\hline Vitamin C (mg) & $118.2 \pm 43.5$ & $152.3 \pm 145.5$ \\
\hline Vitamin D $(\mu \mathrm{g})$ & $6.26 \pm 2.21$ & $3.44 \pm 5.88$ \\
\hline Vitamin E (mg) & $8.73 \pm 1.49$ & $2.74 \pm 2.65$ \\
\hline Zinc (mg) & $9.84 \pm 2.19$ & $9.59 \pm 4.75$ \\
\hline
\end{tabular}

MUFA = mono-unsaturated fatty acid, PUFA = poly-unsaturated fatty acid, RE = retinol equivalent.

Data on the relationship between the DII score and anthropometric measures are shown in Table 3. We found that the DII score was not associated with any of the anthropometric measures (all $p>0.05$ ). This remained after adjustment for age, sex, physical activity and energy intake (Table 3 ). The DII score was also not associated with systolic and diastolic blood pressure, triglycerides and HDL cholesterol (all $p>0.05$ ). These associations also remained non-significant after adjustment for covariates (Table 3 ). However, after correction for age, sex, BMI, energy intake, and physical activity we found that the DII score was positively associated with plasma leptin concentration (Table 3). The sex specific analyses of the relationship between the DII score and all measured parameters are shown in Supplementary Table S2. There were no sex-related differences in the relationships between the DII score and any of the measured parameters.

To further clarify the association between DII score, anthropometric measures, blood pressure, lipid profile and leptin, we divided subjects into three tertiles based on their DII score (Table 4). No significant differences among the 3 tertiles (ANOVA, all $p>0.05$ ) were found. However, after adjustment for age, sex, energy intake, phsyical activity and body mass index, the increase in leptin concentration across DII score tertiles was statistically significant (ANCOVA, $p=0.031$ ). 
Table 3. Standardized regression coefficients (B) and their standard error (SE) and $p$-value of the association between DII score and anthropometric variables, blood pressure, lipid profile, and leptin concentration.

\begin{tabular}{|c|c|c|c|c|c|c|c|c|c|}
\hline \multirow{2}{*}{ Variables } & \multicolumn{3}{|c|}{ Model $0^{a}$} & \multicolumn{3}{|c|}{ Model I $^{b}$} & \multicolumn{3}{|c|}{ Model II c } \\
\hline & $\mathrm{B}^{\mathbf{a}}$ & $\mathrm{SE}^{\mathrm{a}}$ & $p^{a}$ & $\mathbf{B}^{\mathbf{b}}$ & $\mathrm{SE}^{\mathrm{b}}$ & $p^{\mathrm{b}}$ & $\mathrm{B}^{\mathrm{c}}$ & $\mathrm{SE}^{\mathrm{c}}$ & $p^{\mathrm{c}}$ \\
\hline Body weight (kg) & -0.010 & 0.081 & 0.900 & -0.011 & 0.078 & 0.801 & -0.039 & 0.096 & $0.470^{\wedge}$ \\
\hline BMI $\left(\mathrm{kg} / \mathrm{m}^{2}\right)$ & -0.012 & 0.031 & 0.693 & -0.020 & 0.030 & 0.648 & -0.080 & 0.036 & $0.132^{\wedge}$ \\
\hline Body fat $(\%)$ & -0.018 & 0.054 & 0.736 & -0.009 & 0.035 & 0.762 & -0.044 & 0.043 & $0.222^{\wedge}$ \\
\hline Waist circumference $(\mathrm{cm})$ & -0.079 & 0.078 & 0.311 & -0.048 & 0.074 & 0.251 & -0.046 & 0.091 & $0.379^{\wedge}$ \\
\hline Hip circumference $(\mathrm{cm})$ & 0.012 & 0.069 & 0.857 & 0.006 & 0.064 & 0.878 & -0.049 & 0.079 & $0.347^{\wedge}$ \\
\hline Systolic BP (mmHg) & 0.221 & 0.154 & 0.153 & 0.066 & 0.134 & 0.088 & 0.034 & 0.165 & 0.481 * \\
\hline Diastolic BP (mmHg) & 0.128 & 0.091 & 0.159 & 0.065 & 0.082 & 0.107 & 0.046 & 0.102 & $0.355^{*}$ \\
\hline Triglycerides (mmol/L) & -0.004 & 0.005 & 0.407 & -0.037 & 0.005 & 0.388 & 0.045 & 0.006 & $0.406^{*}$ \\
\hline HDL cholesterol (mmol/L) & 0.0003 & 0.003 & 0.925 & 0.010 & 0.003 & 0.825 & -0.046 & 0.004 & 0.400 * \\
\hline Leptin (ng/mL) & 0.101 & 0.061 & 0.102 & 0.105 & 0.042 & 0.002 & 0.096 & 0.052 & 0.020 * \\
\hline
\end{tabular}

${ }^{a}$ Model 0, linear regression analysis without adjustment; ${ }^{b}$ Model I, linear regression analysis with adjustment for age and sex; ${ }^{c}$ Model II, linear regression analysis with correction for age, sex, energy intake, physical activity and $\mathrm{BMI}$ * or without $\mathrm{BMI}$; $\mathrm{BMI}=$ body mass index; $\mathrm{BP}=$ blood pressure; $\mathrm{SE}=$ standard error; DII = Dietary Inflammatory Index.

Table 4. The differences on anthropometric measures, lipid profile, blood pressure and leptin among DII score tertiles.

\begin{tabular}{|c|c|c|c|c|c|}
\hline Variables & $\begin{array}{l}\text { DII Score Tertile } 1 \\
(<-1.0)(n=169)\end{array}$ & $\begin{array}{c}\text { DII Score Tertile } 2 \\
(1.0-5.1)(n=168)\end{array}$ & $\begin{array}{l}\text { DII Score Tertile } 3 \\
\quad(>5.1)(n=164)\end{array}$ & $p_{\text {ANOVA }} *$ & $p_{\text {ANCOVA }}$ \\
\hline \multicolumn{6}{|l|}{ Anthropometric measures } \\
\hline Body weight (kg) & $61.9 \pm 13.9$ & $63.5 \pm 11.0$ & $62.3 \pm 14.2$ & 0.538 & $0.840^{\wedge}$ \\
\hline Body mass index $\left(\mathrm{kg} / \mathrm{m}^{2}\right)$ & $24.7 \pm 4.8$ & $25.3 \pm 4.7$ & $24.9 \pm 5.5$ & 0.523 & $0.470^{\wedge}$ \\
\hline Body fat $(\%)$ & $27.4 \pm 8.6$ & $27.5 \pm 8.7$ & $27.7 \pm 9.0$ & 0.937 & $0.543^{\wedge}$ \\
\hline Waist circumference $(\mathrm{cm})$ & $86.2 \pm 12.7$ & $87.1 \pm 12.4$ & $85.4 \pm 13.2$ & 0.467 & $0.395^{\wedge}$ \\
\hline Hip circumference $(\mathrm{cm})$ & $93.1 \pm 10.3$ & $95.0 \pm 10.7$ & $93.7 \pm 12.5$ & 0.301 & $0.209^{\wedge}$ \\
\hline Systolic blood pressure $(\mathrm{mmHg})$ & $126.9 \pm 25.2$ & $129.3 \pm 24.5$ & $129.5 \pm 25.9$ & 0.590 & $0.847^{\#}$ \\
\hline Diastolic blood pressure $(\mathrm{mmHg})$ & $79.1 \pm 14.3$ & $80.2 \pm 14.4$ & $79.9 \pm 15.8$ & 0.773 & $0.790^{\#}$ \\
\hline Triglycerides $(\mathrm{mmol} / \mathrm{L})$ & $1.6 \pm 0.9$ & $1.6 \pm 0.8$ & $1.5 \pm 0.8$ & 0.479 & $0.413^{\#}$ \\
\hline HDL cholesterol (mmol/L) & $1.2 \pm 0.5$ & $1.1 \pm 0.4$ & $1.2 \pm 0.5$ & 0.378 & $0.572 \#$ \\
\hline Leptin $(\mathrm{ng} / \mathrm{mL})$ & $6.2 \pm 6.9$ & $7.1 \pm 8.5$ & $8.6 \pm 10.7$ & 0.071 & 0.031 \# \\
\hline
\end{tabular}

* ANOVA analysis across DII score tertiles; ^ ANCOVA analysis across DII score tertiles with adjustment for age, sex, energy intake and physical activity; \# ANCOVA analysis across DII score tertiles with adjustment for age, sex, body mass index, energy intake, and physical activity.

\section{Discussion}

This study was aimed to evaluate the relationship between DII score, body weight, blood pressure, lipid profile and leptin in Indonesian adults. We found that DII score was not correlated with any of the anthropometric measures, blood pressure or lipid profile. Interestingly, we showed that the DII was positively correlated with plasma leptin concentration after correction for age, sex and BMI, energy intake and physical activity.

We compared the intake of the components of the DII in our Indonesian population with the global averages described by Shivappa [9]. Participants in this study had higher intake of pro-inflammatory components such as total energy, carbohydrates, iron and vitamin B12 and a lower intake of anti-inflammatory components such as omega 3 fatty acids, omega 6 fatty acids, niacin, vitamin A, vitamin D, and vitamin E. The mean energy intake of men was 11,285 kJ/day and this matches the Indonesian dietary recommendation for male adults (11,406 kJ/day) [27]. The mean energy intake of women was 10,277 kJ/day and this was slightly higher than the Indonesian dietary recommendation for female adults (9418 kJ/day) [27]. Results from this study provide a practical implication that can help reduce the inflammatory properties of diet of individuals in the study population. This can be done by reducing the consumption of carbohydrate rich foods (e.g., rice, sugar and wheat-based products) and increasing consumption of unsaturated fat and protein rich foods (such as eggs and fatty fish). This is because, although protein is considered as pro-inflammatory nutrient, it has a lower inflammatory effect score than carbohydrate [9]. Additionally, unsaturated 
fats are anti-inflammatory nutrients and foods that are rich in unsaturated fats usually also contain fat soluble vitamins such as vitamin A, D, and E [22]. Those vitamins were reported to be lower in these study participants compared to the global dietary intake.

This study was initiated by our earlier finding that in overweight/obese Caucasian men and women who undertook a weight loss program, the DII score was correlated with weight regain during follow-up [15]. In this study we showed that the DII score was not correlated with body weight in Indonesian adult men and women. The relationship between the DII score and obesity indices has also been evaluated elsewhere. In a cross-sectional analysis of the Spanish PREDIMED trial, the DII score was associated with BMI only in women but not in men [13]. In Myanmar, a small cross-sectional study among overweight and non-overweight female school teachers showed that the DII score was not associated with overweight [21]. A role for DII in the development of obesity was indicated by Ramallal et al. [14]. They showed that in a non-overweight adult Spanish cohort the DII score was not associated with BMI at baseline, but a higher DII score was associated with a higher body weight increment after 8 years of follow up and a higher risk of developing overweight or obesity. Based on these studies and our findings, the effect of the DII on body weight remains inconclusive. Well-controlled longer-term intervention studies are required to shed more light on the role of DII in body weight regulation.

There is more convincing evidence that inflammation is an important link between obesity and its cardiovascular co-morbidities [3-6]. Previously it was suggested that low-grade inflammation was associated with the development of dyslipidemia [3]. In this study, we found that the DII score was not correlated with components of the lipid profile, such as triglycerides and HDL. In contrast, Neufcourt et al. showed in a large $(n=3726)$ cohort of French adults [18] that at baseline, the DII score was positively associated with triglyceride level, but not with HDL cholesterol level. After a follow up of 13 years, the DII score was significantly associated with higher triglyceride and lower HDL cholesterol levels. The association between the DII score and lipid profile was also confirmed by a small scale study $(n=90)$ in Colombia [19]. These investigators showed that study participants with a higher pro-inflammatory diet (based on DII score calculation) had a significantly lower HDL level. Our intermediate size study in Indonesian adults could not confirm these findings. On the other hand, there was also no increased risk for low HDL cholesterol or elevated triglyceride concentrations with increasing DII score in a study in 447 U.S. police officers [28]. Dyslipidemia or disturbance of lipid profile including triglyceride and cholesterol levels have long been used as an early biomarker of cardiovascular diseases. However, this concept is now being challenged. Inflammation may be a more important biomarker of cardiovascular diseases [16]. This shift of paradigm is necessary because this might affect dietary approaches for cardiovascular diseases prevention. Instead of aiming to lower cholesterol and triglycerides, it might be more beneficial to lower the inflammatory properties of the diet as a means of prevention of cardiovascular diseases.

In this study we also showed that the DII score was not associated with blood pressure, neither in men nor women. This finding differs from studies previously reporting that the DII score was associated with increased risk for developing hypertension among middle-aged Australian women [20] and Polish adults [29]. On the other hand, Wirth et al. [28] also found no higher risk of elevated blood pressure with increasing DII score in U.S. police officers.

We cannot exclude the possibility that the lack of association between the DII score and lipid profile and blood pressure is due to our inclusion criteria. We only included subjects without a clinical diagnosis cardiovascular diseases, diabetes, or treatment for dyslipidemia or high blood pressure, because we were interested in investigating the role of diet in the early onset development of chronic diseases and thus our population can be regarded as relatively healthy compared to the general Indonesian population.

In this study, we showed that the DII score was positively associated with plasma leptin concentration after adjustment for age, sex, BMI, energy intake, and physical activity. This finding was confirmed by analysis based on DII score tertiles, which showed that leptin concentration increased 
significantly across the tertiles. Leptin is produced by adipose tissue and its production increases with the progression of adiposity [30]. In the past few decades, there has been a growing interest in understanding the interaction between leptin, inflammation and oxidative stress. Leptin is a cytokine which is produced by adipocytes with an ability to induce inflammation. The pro-inflammatory properties of leptin have been suggested to be similar to those of immune cell-derived cytokines such as tumor necrosis factor alpha (TNF- $\alpha$ ) and interleukin 6 (IL-6) [31,32]. In addition to inflammation, it was suggested that leptin plays an important role in the development of oxidative stress in obesity by inducing production of reactive intermediates such as $\mathrm{H}_{2} \mathrm{O}_{2}$ and hydroxyl radicals [33]. The accumulation of these processes can induce development of cardiovascular diseases. This is supported by several studies, which showed that a higher leptin concentration was associated with increased risk for cardiovascular diseases [34-36]. To our knowledge, only one other study has investigated the relationship between DII score and leptin [28]. In this cross-sectional study in U.S. police officers, the DII score was not associated with leptin concentration.

There are several strengths and limitations in this study. The strengths of this study are the relatively large sample size and the non-Western population. However, there are several limitations to this study. First, because data collection was done using a SQ FFQ for Indonesian food consumption with limited data on bioactive components of foods, we cannot provide data on the intake of a number of herbs / seasonings (such as oregano, rosemary, pepper, saffron, garlic, onion, and ginger) as well as polyphenols (such as flavonol, anthocyanidins, and eugenol), which are included in the original list provided by Shivappa et al. [9]. Additionally, there are some food components that have no known value for different types of PUFAs in the food databases used, which might have an impact on total omega 3 and 6 consumption. These might influence the relationships between DII score and outcomes in comparison to the full DII according to Shivappa et al. Second, we reported data on dietary intake amongst individuals who live in urban areas. Therefore, data from this study may not represent the intake of those that live in rural areas. Third, because of the design of this study, no conclusion about causality can be drawn. Fourth, measurements were performed at random times during the day and in the non-fasting state, which may have interfered with the potential association between the DII score and the outcome variables by increasing the variation. However, it was previously shown that in large cohorts the influence of normal food intake on changes in lipids, lipoproteins, and apolipoproteins is small and that the random non-fasting lipid profile remains a good predictor for cardiovascular diseases in humans [37]. However, leptin production has a diurnal variation [38] and is affected by fasting status [39], and therefore confirmation of our findings under better standardized conditions is needed.

\section{Conclusions}

In summary, we showed that the DII score was positively correlated with the plasma leptin concentration, which is one of the markers of adipose tissue inflammation. This might explain the connection between the DII score and increased systemic inflammation as well as cardiovascular diseases in other studies. Because of the potential importance of diet in the development of inflammation, intervention studies that investigate the effect of manipulation of the inflammatory properties of the diet on the inflammatory process are warranted.

Supplementary Materials: The following are available online at http:/ / www.mdpi.com/2072-6643/11/1/148/s1, Table S1: The comparison of anthropometric measures, blood pressure, lipid profile, dietary intake, physical activity and leptin between men and women, Table S2: Linear regression analysis with the DII score as independent variable for men and women.

Author Contributions: Conceptualization, H.F.L.M., D.C.S., E.H., Y.Y.L., and W.A.M.W.M.; Methodology, H.F.L.M., D.C.S., E.H., Y.Y.L., and W.A.M.W.M.; Software, H.F.L.M.; Validation, H.F.L.M., D.C.S., and E.H.; Formal Analysis, H.F.L.M., M.A.v.B., and E.C.M.; Investigation, H.F.L.M., D.C.S., E.H., Y.Y.L., and W.A.M.W.M.; Resources, H.F.L.M. and W.A.M.W.M.; Data Curation, H.F.L.M., M.A.v.B., and E.C.M.; Writing-Original Draft Preparation, H.F.L.M., M.A.v.B., and E.C.M.; Writing-Review and Editing, H.F.L.M., M.A.v.B., and E.C.M.; 
Visualization, H.F.L.M., M.A.v.B., and E.C.M.; Supervision, W.A.M.W.M.; Project Administration, H.F.L.M., and Y.Y.L.; Funding Acquisition, H.F.L.M., and W.A.M.W.M.

Funding: This study was funded by International Research Collaboration (IRec) Grant (IREC Grant No.: 1002/PPSK/ 910408) (Universiti Sains Malaysia) and Community Fund-Faculty of Medicine (Universitas Gadjah Mada).

Acknowledgments: We thank to Cita Eri Ayuningtyas, Satwika Arya Pratama and Maya Nurfitriani Hartono for their support with data collection.

Conflicts of Interest: The authors declare no conflict of interest.

\section{References}

1. GBD 2015 Obesity Collaborators. Health Effects of Overweight and Obesity in 195 Countries over 25 Years. N. Engl. J. Med. 2017, 377, 13-27. [CrossRef] [PubMed]

2. Tremmel, M.; Gerdtham, U.G.; Nilsson, P.M.; Saha, S. Economic Burden of Obesity: A Systematic Literature Review. Int. J. Environ. Res. Public Health 2017, 14. [CrossRef]

3. Monteiro, R.; Azevedo, I. Chronic inflammation in obesity and the metabolic syndrome. Mediators Inflamm. 2010, 2010. [CrossRef] [PubMed]

4. Han, J.M.; Levings, M.K. Immune regulation in obesity-associated adipose inflammation. J. Immunol. 2013, 191, 527-532. [CrossRef] [PubMed]

5. Lumeng, C.N.; Bodzin, J.L.; Saltiel, A.R. Obesity induces a phenotypic switch in adipose tissue macrophage polarization. J. Clin. Investig. 2007, 117, 175-184. [CrossRef]

6. Morris, D.L.; Singer, K.; Lumeng, C.N. Adipose tissue macrophages: Phenotypic plasticity and diversity in lean and obese states. Curr. Opin. Clin. Nutr. Metab. Care 2011, 14, 341-346. [CrossRef]

7. Pankow, J.S.; Folsom, A.R.; Cushman, M.; Borecki, I.B.; Hopkins, P.N.; Eckfeldt, J.H.; Tracy, R.P. Familial and genetic determinants of systemic markers of inflammation: The NHLBI family heart study. Atherosclerosis 2001, 154, 681-689. [CrossRef]

8. Cavicchia, P.P.; Steck, S.E.; Hurley, T.G.; Hussey, J.R.; Ma, Y.; Ockene, I.S.; Hébert, J.R. A New Dietary Inflammatory Index Predicts Interval Changes in Serum High-Sensitivity C-Reactive Protein. J. Nutr. 2009, 139, 2365-2372. [CrossRef]

9. Shivappa, N.; Steck, S.E.; Hurley, T.G.; Hussey, J.R.; Hébert, J.R. Designing and developing a literaturederived, population-based dietary inflammatory index. Public Health Nutr. 2014, 17, 1689-1696. [CrossRef]

10. Shivappa, N.; Steck, S.E.; Hurley, T.G.; Hussey, J.R.; Ma, Y.; Ockene, I.S.; Tabung, F.; Hébert, J.R. A populationbased dietary inflammatory index predicts levels of C-reactive protein in the Seasonal Variation of Blood Cholesterol Study (SEASONS). Public Health Nutr. 2014, 17, 1825-1833. [CrossRef]

11. Shivappa, N.; Hébert, J.R.; Rietzschel, E.R.; De Buyzere, M.L.; Langlois, M.; Debruyne, E.; Marcos, A.; Huybrechts, I. Associations between dietary inflammatory index and inflammatory markers in the Asklepios Study. Br. J. Nutr. 2015, 113, 665-671. [CrossRef] [PubMed]

12. Tabung, F.K.; Smith-Warner, S.A.; Chavarro, J.E.; Fung, T.T.; Hu, F.B.; Willett, W.C.; Giovannucci, E.L. An Empirical Dietary Inflammatory Pattern Score Enhances Prediction of Circulating Inflammatory Biomarkers in Adults. J. Nutr. 2017, 147, 1567-1577. [CrossRef] [PubMed]

13. Ruiz-Canela, M.; Zazpe, I.; Shivappa, N.; Hébert, J.R.; Sánchez-Tainta, A.; Corella, D.; Salas-Salvadó, J.; Fitó, M.; Lamuela-Raventós, R.M.; Rekondo, J.; et al. Dietary inflammatory index and anthropometric measures of obesity in a population sample at high cardiovascular risk from the PREDIMED (PREvención con DIeta MEDiterránea) trial. Br. J. Nutr. 2015, 113, 984-995. [CrossRef] [PubMed]

14. Ramallal, R.; Toledo, E.; Martínez, J.A.; Shivappa, N.; Hébert, J.R.; Martínez-González, M.A.; Ruiz-Canela, M. Inflammatory potential of diet, weight gain, and incidence of overweight/obesity: The SUN cohort. Obesity (Silver Spring) 2017, 25, 997-1005. [CrossRef] [PubMed]

15. Muhammad, H.F.L.; Vink, R.G.; Roumans, N.J.T.; Arkenbosch, L.A.J.; Mariman, E.C.; van Baak, M.A. Dietary Intake after Weight Loss and the Risk of Weight Regain: Macronutrient Composition and Inflammatory Properties of the Diet. Nutrients 2017. [CrossRef] [PubMed]

16. Tsoupras, A.; Lordan, R.; Zabetakis, I. Inflammation, not Cholesterol, Is a Cause of Chronic Disease. Nutrients 2018, 10. [CrossRef] [PubMed]

17. Savoia, C.; Schiffrin, E.L. Vascular inflammation in hypertension and diabetes: Molecular mechanisms and therapeutic interventions. Clin. Sci. (Lond) 2007, 112, 375-384. [CrossRef] 
18. Neufcourt, L.; Assmann, K.E.; Fezeu, L.K.; Touvier, M.; Graffouillère, L.; Shivappa, N.; Hébert, J.R.; Wirth, M.D.; Hercberg, S.; Galan, P.; et al. Prospective association between the dietary inflammatory index and metabolic syndrome: Findings from the SU.VI.MAX study. Nutr. Metab. Cardiovasc. Dis. 2015, 25, 988-996. [CrossRef]

19. Camargo-Ramos, C.M.; Correa-Bautista, J.E.; Correa-Rodríguez, M.; Ramírez-Vélez, R. Dietary Inflammatory Index and Cardiometabolic Risk Parameters in Overweight and Sedentary Subjects. Int. J. Environ. Res. Public Health 2017, 14. [CrossRef]

20. Vissers, L.E.T.; Waller, M.; van der Schouw, Y.T.; Hébert, J.R.; Shivappa, N.; Schoenaker, D.A.J.M.; Mishra, G.D. A pro-inflammatory diet is associated with increased risk of developing hypertension among middle-aged women. Nutr. Metab. Cardiovasc. Dis. 2017, 27, 564-570. [CrossRef]

21. San, K.M.M.; Fahmida, U.; Wijaksono, F.; Lin, H.; Zaw, K.K.; Htet, M.K. Chronic low grade inflammation measured by dietary inflammatory index and its association with obesity among school teachers in Yangon, Myanmar. Asia Pac. J. Clin. Nutr. 2018, 27, 92-98. [CrossRef] [PubMed]

22. United States Department of Agriculture. Available online: https://ndb.nal.usda.gov/ndb/search/list (accessed on 3 January 2018).

23. Steinemann, N.; Grize, L.; Ziesemer, K.; Kauf, P.; Probst-Hensch, N.; Brombach, C. Relative validation of a food frequency questionnaire to estimate food intake in an adult population. Food Nutr. Res. 2017. [CrossRef] [PubMed]

24. Wanner, M.; Probst-Hensch, N.; Kriemler, S.; Meier, F.; Autenrieth, C.; Martin, B.W. Validation of the long international physical activity questionnaire: Influence of age and language region. Prev. Med. Rep. 2016, 3, 250-256. [CrossRef] [PubMed]

25. Luglio, H.F.; Eurike, D.; Huriyati, E.; Julia, M.; Susilowati, R. Gene-lifestyle interaction: The role of SNPs in UCP2 -866G/A and UCP3 -55C/T on dietary intake and physical activity in Indonesian obese female adolescents. Med. J. Nutr. Metab. 2016, 9, 87-93. [CrossRef]

26. University of Amsterdam: JASP 0.9.0.1. Available online: https:/ /jasp-stats.org (accessed on 15 August 2018).

27. Indonesian Ministry of Health. Angka Kecukupan Gizi. 2013. Available online: http://gizi.depkes.go.id/ download/Kebijakan\%20Gizi/PMK\%2075-2013.pdf (accessed on 29 April 2018).

28. Sokol, A.; Wirth, M.D.; Manczuk, M.; Shivappa, N.; Zatonska, K.; Hurley, T.G.; Hébert, J.R. Association between the dietary inflammatory index, waist-to-hip ratio and metabolic syndrome. Nutr. Res. 2016, 36, 1298-1303. [CrossRef]

29. Wirth, M.D.; Burch, J.; Shivappa, N.; Violanti, J.M.; Burchfiel, C.M.; Fekedulegn, D.; Andrew, M.E.; Hartley, T.A.; Miller, D.B.; Mnatsakanova, A.; et al. Association of a dietary inflammatory index with inflammatory indices and metabolic syndrome among police officers. J. Occup. Environ. Med. 2014, 56, 986-989. [CrossRef] [PubMed]

30. Considine, R.V.; Sinha, M.K.; Heiman, M.L.; Kriauciunas, A.; Stephens, T.W.; Nyce, M.R.; Ohannesian, J.P.; Marco, C.C.; McKee, L.J.; Bauer, T.L.; et al. Serum immunoreactive-leptin concentrations in normal-weight and obese humans. N. Engl. J. Med. 1996, 334, 292-295. [CrossRef] [PubMed]

31. Iikuni, N.; Lam, Q.L.; Lu, L.; Matarese, G.; La Cava, A. Leptin and Inflammation. Curr. Immunol. Rev. 2008, 4, 70-79. [CrossRef] [PubMed]

32. Wellen, K.E.; Hotamisligil, G.S. Inflammation, stress, and diabetes. J. Clin. Investig. 2005, 115, 1111-1119. [CrossRef] [PubMed]

33. Fortuño, A.; Bidegain, J.; Baltanás, A.; Moreno, M.U.; Montero, L.; Landecho, M.F.; Beloqui, O.; Díez, J.; Zalba, G. Is leptin involved in phagocytic NADPH oxidase overactivity in obesity? Potential clinical implications. J. Hypertens. 2010, 28, 1944-1950. [CrossRef] [PubMed]

34. Hou, N.; Luo, J.D. Leptin and cardiovascular diseases. Clin. Exp. Pharmacol. Physiol. 2011, 38, 905-913. [CrossRef]

35. Reilly, M.P.; Iqbal, N.; Schutta, M.; Wolfe, M.L.; Scally, M.; Localio, A.R.; Rader, D.J.; Kimmel, S.E. Plasma leptin levels are associated with coronary atherosclerosis in type 2 diabetes. J. Clin. Endocrinol. Metab. 2004, 89, 3872-3878. [CrossRef]

36. Wallerstedt, S.M.; Eriksson, A.L.; Niklason, A.; Ohlsson, C.; Hedner, T. Serum leptin and myocardial infarction in hypertension. Blood Press. 2004, 13, 243-246. [CrossRef] [PubMed] 
37. Langsted, A.; Freiberg, J.J.; Nordestgaard, B.G. Fasting and nonfasting lipid levels: Influence of normal food intake on lipids, lipoproteins, apolipoproteins, and cardiovascular risk prediction. Circulation 2008, 118, 2047-2056. [CrossRef] [PubMed]

38. Langendonk, J.G.; Pijl, H.; Toornvliet, A.C.; Burggraaf, J.; Frölich, M.; Schoemaker, R.C.; Doornbos, J.; Cohen, A.F.; Meinders, A.E. Circadian Rhythm of Plasma Leptin Levels in Upper and Lower Body Obese Women: Influence of Body Fat Distribution and Weight Loss. J. Clin. Endocrinol. Metab. 1998, 83, 1706-1712. [CrossRef]

39. Korek, E.; Krauss, H.; Gibas-Dorna, M.; Kupsz, J.; Piątek, M.; Piątek, J. Fasting and postprandial levels of ghrelin, leptin and insulin in lean, obese and anorexic subjects. Prz. Gastroenterol. 2013, 8, 383-389. [CrossRef] [PubMed] 